\title{
Cigarette smoking among secondary schoolchildren 1975-79
}

\author{
R G RAWBONE AND A GUZ \\ Department of Medicine, Charing Cross Hospital Medical School, London
}

SUMMARY A questionnaire relating to smoking habits, respiratory symptoms, and health attitudes was administered to schoolchildren aged between 11 and 17 throughout a defined geographical area in both 1975 and 1979, with a valid response from 10498 and 12002 young people respectively. Each cohort was almost entirely different. The results suggest that although the prevalence of $\dot{c}$ regular smoking has decreased in boys from 16 to $13 \%$ it has increased in girls from 13 to $14 \%$, and $\mathrm{N}$ that at all ages more girls smoke than boys. However despite the fall in the prevalence of regular 윽 smoking in boys there has been an overall increase in cigarette consumption. Young people who are regular smokers predominantly smoke middle tar cigarettes while among experimental smokers there is a high incidence of low tar smoking, which might suggest that such cigarettes facilitate the taking up of the habit by children. The previously described relationships between smoking and respiratory symptoms was confirmed. During the 4-year study period young people's knowledge of the associated links between smoking and heart disease and stroke has increased appreciably. It is suggested that specific health education during the years 1975-79 has not been successful, and there is the need for research.

During the last 5 years a large amount of antismoking propaganda has continued to appear in the UK and much of it has been directed towards young people and the social aspects of the smoking habit. In addition health education in schools is being given more prominence and some of this will also be devoted to the subject of tobacco smoking. This emphasis on smoking and young people has been the result of increasing awareness of the prevalence of smoking in the younger age groups ${ }^{1}$ together with the importance which this early initiation into the habit has with respect to persistent adult smoking and its associated early morbidity and mortality. The immediate effects of cigarette smoking on the health of young smokers is also being increasingly recognised. ${ }^{2}$

In 1975 we surveyed by self-administered questionnaires the smoking habits, together with respiratory symptoms and knowledge of smoking-associated health risks, of 10498 schoolchildren attending the outer London borough of Hounslow secondary schools. ${ }^{2} 3$ By 1979 it became of interest to resurvey the equivalent population of schoolchildren within the same borough. We planned to establish whether, during the intervening 4-year period, there had been any change in smoking prevalence or increase in the proportion of young people who associate smoking with certain diseases.

\section{Method}

The outer London borough of Hounslow is a largely urban area with industry centering around London's Heathrow airport. There is a broad spectrum of social class. The state secondary school population of the borough is contained within 15 schools of which 9 may be classified as mixed comprehensive, 2 as boys-only comprehensive, 2 as girls-only com- I prehensive, and one each of single-sex grammar schools. Despite the general trend towards comprehensive education this distribution of school types remained throughout the 4-year study period.

Thirteen schools took part in each of two crosssectional studies. One of the mixed comprehensive schools did not participate in either survey while a 0 further mixed comprehensive school took part in the second survey but not in the first, and one of the girls-only comprehensive schools took part in the first survey but not in the second.

The study protocol was identical for both surveys. Details of the project were circulated to children's parents who were given the opportunity both of 
seeing the questionnaire and of withdrawing their child from the study. The questionnaire was administered in the schools during the last week in March 1975 and again during the first week in April 1979. It was answered anonymously under the supervision of form teachers. On completion of the questionnaire each child sealed his or her response in a plain envelope to ensure confidentiality and the envelopes were collected from the school the same day. Each questionnaire was finally scrutinised to ensure that it had been completed satisfactorily and could be transcribed to punch cards for computer analysis.

Although the 1975 survey had been extensively analysed and reported it was decided that in order to maximise comparability between the two studies further analyses would be performed simultaneously on both studies using identical computer programs. These were performed on the ICL 1906 S computer at Queens University of Belfast computer centre using a statistical package for the social sciences (SPSS). ${ }^{4}$

Statistics. Statistical analyses have been performed using a $\chi^{2}$ test to analyse group data. Comparisons between the two surveys have been performed by manually constructing an $\mathrm{r} \times 2$ contingency table from the SPSS outputs and then applying the $\chi^{2}$ test. $\chi^{2}$ values with more than 1 degree of freedom were partitioned according to the method described by Maxwell. ${ }^{5}$ To compare the responses of nonsmokers with those of regular smokers, correcting for age differences, the age series of $2 \times 2$ contingency tables has been pooled using Cochran's method $^{6}$ which is based on a weighted mean of the differences between the proportions in each group. The level of significance has been taken as $\mathbf{P}<0.05$.

Discrepancies in the various analyses were found in the total number of children. This arose entirely because small numbers of children $(<1 \%)$ failed to respond to isolated questions (for example, age) within an otherwise valid questionnaire.

\section{Results}

From the first cross-sectional study in 1975 a total of 10498 valid questionnaires was obtained for analysis, representing a response rate of $77 \cdot 8 \%$ of the total number of children within the secondary school population at that time. The 1979 cross-sectional survey yielded a total of 12002 valid questionnaires representing a response rate of $83.5 \%$.

Smoking rates. Children were asked to place themselves in one of the following categories: (a) I have never smoked a cigarette; (b) I have tried a cigarette once; (c) I smoke occasionally but not as much as 1 a week; (d) I used to smoke but I do not at all now; (e) I usually smoke between 1 and 6 cigarettes a week; (f) I usually smoke at least 7 cigarettes a week but fewer than 40 ; (g) I usually smoke more than 40 cigarettes a week. To simplify analyses and to enable comparisons to be made with other studies these 7 categories were reduced to 4 for most analyses (1) non-smoker (a); (2) experimental smoker (b and c); (3) ex-smoker (d); (4) regular smoker (e, f, and g).

The numbers of boys and girls in these 4 categories are shown for both studies in Table 1. In 1975 about $15 \%$ admitted to regular smoking $(16.3 \%$ of boys $13.3 \%$ of girls) while in 1979 the figure was about $13.5 \%(13.1 \%$ of boys $13.7 \%$ of girls). A comparison of the distribution of smoking habits between the two studies shows that there is a significant difference $\left(\chi^{2}=33 \cdot 68,7 \mathrm{df}, \mathrm{P}<0.001\right)$. Partitioning the $\chi^{2}$ value indicates that there is no significant difference between the studies in the distribution of boys and girls and neither is there any difference in the distribution of smoking categories within the girls. The major significant difference lies within the distribution of smoking categories within the boys $\left(\chi^{2}=28.54,3 \mathrm{df}, \mathrm{P}<0.001\right)$ and this is principally due to a change in the prevalence of regular smoking which has fallen from 16 to $13 \%$.

Table 2 shows, for the regular smokers, the cigarette consumption for boys and girls in the two

Table 1 Distribution of boys and girls between the four groups-non-smokers, experimental smokers, ex-smokers, and regular smokers-for the two studies

\begin{tabular}{|c|c|c|c|c|}
\hline \multirow{2}{*}{ Cross-sectional study } & \multicolumn{4}{|c|}{ Percentage of children } \\
\hline & Non-smokers & Experimental smokers & Ex-smokers & Regular smokers \\
\hline $\begin{array}{l}\text { First }(1975) \\
\text { Boys }(n=5594) \\
\text { Girls }(n=4819)\end{array}$ & $\begin{array}{l}35 \cdot 3 \\
43 \cdot 5\end{array}$ & $\begin{array}{l}33 \cdot 3 \\
30 \cdot 9\end{array}$ & $\begin{array}{l}14 \cdot 8 \\
12 \cdot 3\end{array}$ & $\begin{array}{l}16 \cdot 3 \\
13 \cdot 3\end{array}$ \\
\hline $\begin{array}{l}\text { Second }(1979) \\
\text { Boys }(n=6376) \\
\text { Girls }(n=5540)\end{array}$ & $\begin{array}{l}35 \cdot 5 \\
41 \cdot 6\end{array}$ & $\begin{array}{l}36 \cdot 5 \\
31 \cdot 9\end{array}$ & $\begin{array}{l}14 \cdot 9 \\
12 \cdot 8\end{array}$ & $\begin{array}{l}13 \cdot 1 \\
13 \cdot 7\end{array}$ \\
\hline
\end{tabular}


Table 2 Extent of smoking in regular smokers in boys and girls for the two studies

\begin{tabular}{|c|c|c|c|}
\hline \multirow{2}{*}{$\begin{array}{l}\text { Cross-sectional } \\
\text { study }\end{array}$} & \multicolumn{3}{|c|}{ Percentage of children } \\
\hline & $\begin{array}{l}\text { l-6 } \\
\text { cigarettes/ } \\
\text { week }\end{array}$ & $\begin{array}{l}7-40 \\
\text { cigarettes/ } \\
\text { week }\end{array}$ & $\begin{array}{l}40+ \\
\text { cigarettes/ } \\
\text { week }\end{array}$ \\
\hline \multicolumn{4}{|l|}{ First (1975) } \\
\hline $\begin{array}{l}\text { Boys }(n=912) \\
\text { Girls }(n=640)\end{array}$ & $\begin{array}{l}33 \cdot 6 \\
35 \cdot 1\end{array}$ & $\begin{array}{l}35 \cdot 6 \\
41 \cdot 1\end{array}$ & $\begin{array}{l}30 \cdot 8 \\
23 \cdot 8\end{array}$ \\
\hline \multicolumn{4}{|l|}{ Second (1979) } \\
\hline $\begin{array}{l}\text { Boys }(n=836) \\
\text { Girls }(n=759)\end{array}$ & $\begin{array}{l}26 \cdot 8 \\
32 \cdot 3\end{array}$ & $\begin{array}{l}40 \cdot 2 \\
45 \cdot 6\end{array}$ & $\begin{array}{l}33 \cdot 0 \\
22 \cdot 1\end{array}$ \\
\hline
\end{tabular}

studies. In both studies $28 \%$ of the regular smokers admit to smoking more than 40 cigarettes per week. Comparing the studies indicates a significant difference $\left(\chi^{2}=25.2,5 \mathrm{df}, \mathrm{P}<0.001\right)$; partitioning and excluding the differences between boys and girls shows that there has been no significant change in the distribution of cigarette consumption within girls $\left(\chi^{2}=2 \cdot 8\right)$ while in boys there has been a significant change $\left(\chi^{2}=9.84,2\right.$ df, $\left.P<0.001\right)$ which from the figures given in Table 2 would appear to be in the direction of an overall increase.

A breakdown of smoking habit by age in years $\stackrel{\bar{\triangle}}{\Omega}$ over the two studies is shown for boys in Table 3 and? for girls in Table 4. In both tables pupils aged 17 흠 years and over are grouped together. The prevalence $\frac{\bar{\omega}}{\overrightarrow{ }}$ of smoking in both boys and girls increases up to the $\stackrel{\mathbb{\Phi}}{\propto}$ school-leaving age of 16 years, and this is apparent in both studies. Comparing the two studies indicates. highly significant statistical differences between them . for both genders $\left(\chi^{2}=129\right.$ for boys, $\chi^{2}=120$ for $\overrightarrow{\vec{\omega}}$ girls, both on $27 \mathrm{df}$ ); however partitioning shows $\stackrel{\omega}{\sigma}$ that these differences in boys are to a large extent due to differences in age distributions $\left(\chi^{2}=62, \stackrel{?}{0}\right.$ $6 \mathrm{df}$ ) while in girls they are completely accounted for by different age distributions $\left(\chi^{2}=100,6 \mathrm{df}\right)$. In the case of boys detailed partitioning indicates that there $C$ are significant differences in smoking habit at all ages (except age 11 years) and that this is consistently due to a decrease in the prevalence of regular smokers. There is a smaller, and less significant, increase in the

Table 3 Distribution of boys between the four groups-non-smokers, experimental smokers, ex-smokers, and regular smokers-with respect to age

\begin{tabular}{|c|c|c|c|c|c|c|}
\hline \multirow{2}{*}{ Cross-sectional study } & \multirow{2}{*}{ Age (years) } & \multirow{2}{*}{ Total number } & \multicolumn{4}{|c|}{ Percentage of children } \\
\hline & & & Non-smoker & $\begin{array}{l}\text { Experimental } \\
\text { smoker }\end{array}$ & Ex-smoker & Regular smoker \\
\hline First (1975) & $\begin{array}{l}11 \\
12 \\
13 \\
14 \\
15 \\
16 \\
17+\end{array}$ & $\begin{array}{r}569 \\
1108 \\
1081 \\
1036 \\
854 \\
558 \\
344\end{array}$ & $\begin{array}{l}49 \cdot 2 \\
40 \cdot 4 \\
34 \cdot 0 \\
27 \cdot 7 \\
31 \cdot 3 \\
32 \cdot 6 \\
38 \cdot 1\end{array}$ & $\begin{array}{l}33 \cdot 9 \\
34 \cdot 2 \\
35 \cdot 0 \\
35 \cdot 2 \\
28 \cdot 8 \\
31 \cdot 9 \\
34 \cdot 9\end{array}$ & $\begin{array}{r}12 \cdot 3 \\
17 \cdot 1 \\
16 \cdot 3 \\
17 \cdot 7 \\
13 \cdot 7 \\
11 \cdot 6 \\
7 \cdot 0\end{array}$ & $\begin{array}{r}4 \cdot 6 \\
8 \cdot 2 \\
14 \cdot 7 \\
19 \cdot 4 \\
26 \cdot 2 \\
23 \cdot 8 \\
20 \cdot 0\end{array}$ \\
\hline Second (1979) & $\begin{array}{l}11 \\
12 \\
13 \\
14 \\
15 \\
16 \\
17+\end{array}$ & $\begin{array}{r}461 \\
1175 \\
1231 \\
1124 \\
1176 \\
732 \\
451\end{array}$ & $\begin{array}{l}52.7 \\
45.4 \\
35.3 \\
29.4 \\
29.2 \\
29.9 \\
33.0\end{array}$ & $\begin{array}{l}31 \cdot 5 \\
35 \cdot 8 \\
39 \cdot 0 \\
37 \cdot 3 \\
34 \cdot 2 \\
35 \cdot 2 \\
42 \cdot 0\end{array}$ & $\begin{array}{r}11 \cdot 9 \\
14 \cdot 4 \\
16 \cdot 7 \\
17 \cdot 5 \\
15 \cdot 6 \\
13 \cdot 3 \\
8 \cdot 9\end{array}$ & $\begin{array}{r}3.9 \\
4.3 \\
9.0 \\
15.8 \\
21.1 \\
21.6 \\
15.7\end{array}$ \\
\hline
\end{tabular}

Table 4 Distribution of girls between the four groups-non-smokers, experimental smokers, ex-smokers, and regular smokers-with respect to age

\begin{tabular}{|c|c|c|c|c|c|c|}
\hline \multirow{2}{*}{ Cross-sectional study } & \multirow{2}{*}{ Age (years) } & \multirow{2}{*}{ Total number } & \multicolumn{4}{|c|}{ Percentage of children } \\
\hline & & & Non-smoker & $\begin{array}{l}\text { Experimental } \\
\text { smoker }\end{array}$ & Ex-smoker & Regular smoker \\
\hline First (1975) & $\begin{array}{l}11 \\
12 \\
13 \\
14 \\
15 \\
16 \\
17+\end{array}$ & $\begin{array}{r}481 \\
1063 \\
964 \\
858 \\
673 \\
515 \\
242\end{array}$ & $\begin{array}{l}65 \cdot 5 \\
54 \cdot 6 \\
42 \cdot 1 \\
36 \cdot 1 \\
32 \cdot 7 \\
28 \cdot 7 \\
44 \cdot 2\end{array}$ & $\begin{array}{l}24 \cdot 1 \\
30 \cdot 2 \\
30 \cdot 9 \\
30 \cdot 8 \\
30 \cdot 2 \\
37.5 \\
36 \cdot 4\end{array}$ & $\begin{array}{r}7 \cdot 3 \\
10 \cdot 7 \\
15 \cdot 5 \\
12.9 \\
14 \cdot 1 \\
11 \cdot 8 \\
9.1\end{array}$ & $\begin{array}{r}3 \cdot 1 \\
4 \cdot 5 \\
11 \cdot 5 \\
20 \cdot 2 \\
23 \cdot 0 \\
21 \cdot 9 \\
10 \cdot 3\end{array}$ \\
\hline Second (1979) & $\begin{array}{l}11 \\
12 \\
13 \\
14 \\
15 \\
16 \\
17+\end{array}$ & $\begin{array}{r}379 \\
1051 \\
988 \\
990 \\
978 \\
696 \\
402\end{array}$ & $\begin{array}{l}60 \cdot 2 \\
51 \cdot 7 \\
40 \cdot 6 \\
35 \cdot 8 \\
33 \cdot 3 \\
35 \cdot 5 \\
45 \cdot 3\end{array}$ & $\begin{array}{l}26 \cdot 1 \\
30 \cdot 8 \\
32 \cdot 6 \\
32 \cdot 8 \\
30 \cdot 6 \\
33 \cdot 3 \\
33 \cdot 1\end{array}$ & $\begin{array}{r}10 \cdot 8 \\
12 \cdot 6 \\
15 \cdot 0 \\
14 \cdot 1 \\
13 \cdot 3 \\
12 \cdot 5 \\
8 \cdot 2\end{array}$ & $\begin{array}{r}2.9 \\
4.9 \\
11.8 \\
17.3 \\
22.8 \\
18.7 \\
13.4\end{array}$ \\
\hline
\end{tabular}


prevalence of experimental smokers; the prevalence of non-smokers is not significantly different.

Regular smokers were asked to record whether they normally smoked the same brand of cigarettes and, if so, to state the name of the brand. Although subject to error the brands given were coded according to the five tar categories published by the laboratory of the Government Chemist ${ }^{7}$ and current at that time (that is May 1975 and May 1979). The results for the two studies are shown for regular smokers in Table 5 . Overall about $70 \%$ of regular smokers stated that they generally smoked the same brand and this was in contrast to the experimental smokers for whom the figure was about $35 \%$. Of the regular smokers apparently showing brand loyalty, about $85 \%$ in both studies were smoking a middle tar cigarette; in 1975 the majority of the remainder were smoking products from within the low-middle tar category while in 1979 the low tar category contained $6 \%$ of brand-loyal, regular smokers with an equivalent reduction in the low-middle tar group.

Respiratory symptoms. Children were asked to indicate the most appropriate of the following statements. I hardly ever cough; I cough a little on most days; I cough a little every day. In addition they were asked to respond-yes or no-to the following questions. Do you often suffer from a cold?; When suffering from a cold, do you normally cough up phlegm (spit)?; Do you get short of breath when hurrying on level ground or walking up a slight hill?

We have previously presented a detailed analysis of such respiratory symptoms by gender, age, and smoking category for the first (1975) cross-sectional study. ${ }^{2}$ In summary the results showed that those children who smoked regularly had a higher prevalence of upper respiratory tract infections and a higher incidence of the respiratory symptoms, cough, phlegm production with a cold, and shortness of breath, compared with non-smokers. An equivalent analysis of the second (1979) cross-sectional study shows a similar pattern of results and, after correction for differences in age distribution and differences in smoking pattern, a comparison between the two surveys shows only few significant differences between them. A summary of the prevalence of these 'symptoms' together with relevant statistics is given for the two studies in Table 6.

Awareness of association between smoking and certain diseases. Pupils were asked to indicate, from a list of diseases, those which they considered could be caused by smoking. The list consisted of the following conditions: appendicitis, chestiness (wheezing), heart disease, stroke, lung cancer, deafness, and bronchitis. Appendicitis and deafness were included in an attempt to prevent children ticking every condition indiscriminantly; in fact fewer than $1 \%$ from each study ticked everything.

The proportion of children indicating a positive response for each of the conditions by gender and smoking group for the two studies, together with relevant statistics, is given in Table 7. Once again a very similar pattern of results can be observed between the two studies and there are no significant differences between them in terms of non-smoker/

Table 5a Percentage of regular smokers normally smoking the same brand of cigarettes and the tar category of that brand for both studies and by gender

\begin{tabular}{|c|c|c|c|c|c|}
\hline \multirow{2}{*}{ Cross-sectional study } & \multirow{2}{*}{$\begin{array}{l}\% \text { of regular } \\
\text { smokers normally } \\
\text { smoking same brand }\end{array}$} & \multicolumn{4}{|c|}{$\%$ smoking } \\
\hline & & Low tar & Low-middle tar & Middle tar & Other products \\
\hline \multicolumn{6}{|l|}{ First (1975) } \\
\hline $\begin{array}{l}\text { Boys } \\
\text { Girls }\end{array}$ & $\begin{array}{l}71 \cdot 3 \\
73 \cdot 2\end{array}$ & $\begin{array}{l}0.2 \\
0.2\end{array}$ & $\begin{array}{l}12 \cdot 0 \\
16 \cdot 9\end{array}$ & $\begin{array}{l}84 \cdot 5 \\
81 \cdot 4\end{array}$ & $\begin{array}{l}3 \cdot 3 \\
1 \cdot 5\end{array}$ \\
\hline \multicolumn{6}{|l|}{ Second (1979) } \\
\hline $\begin{array}{l}\text { Boys } \\
\text { Girls }\end{array}$ & $\begin{array}{l}70 \cdot 4 \\
70 \cdot 5\end{array}$ & $\begin{array}{l}6 \cdot 1 \\
5 \cdot 5\end{array}$ & $\begin{array}{l}7 \cdot 0 \\
5 \cdot 3\end{array}$ & $\begin{array}{l}86 \cdot 7 \\
89 \cdot 2\end{array}$ & $\begin{array}{l}0.2 \\
0\end{array}$ \\
\hline
\end{tabular}

Table 5b Percentage of experimental smokers normally smoking the same brand of cigarettes and the tar category of that brand for both studies and by gender

\begin{tabular}{|c|c|c|c|c|c|}
\hline \multirow{2}{*}{ Cross-sectional study } & \multirow{2}{*}{$\begin{array}{l}\% \text { of experimental } \\
\text { smokers normally } \\
\text { smoking same brand }\end{array}$} & \multicolumn{4}{|c|}{$\%$ smoking } \\
\hline & & Low tar & Low-middle tar & Middle tar & Other products \\
\hline \multicolumn{6}{|l|}{ First (1975) } \\
\hline $\begin{array}{l}\text { Boys } \\
\text { Girls }\end{array}$ & $\begin{array}{l}27.4 \\
40 \cdot 5\end{array}$ & $\begin{array}{l}3 \cdot 3 \\
3 \cdot 5\end{array}$ & $\begin{array}{l}16 \cdot 7 \\
21 \cdot 3\end{array}$ & $\begin{array}{l}75 \cdot 8 \\
69 \cdot 5\end{array}$ & $\begin{array}{l}4 \cdot 2 \\
5 \cdot 7\end{array}$ \\
\hline \multicolumn{6}{|l|}{ Second (1979) } \\
\hline $\begin{array}{l}\text { Boys } \\
\text { Girls }\end{array}$ & $\begin{array}{l}35 \cdot 3 \\
39 \cdot 1\end{array}$ & $\begin{array}{l}16 \cdot 1 \\
22 \cdot 1\end{array}$ & $\begin{array}{l}6 \cdot 5 \\
5 \cdot 0\end{array}$ & $\begin{array}{l}77.4 \\
72 \cdot 9\end{array}$ & $\begin{array}{l}\mathbf{0} \\
\mathbf{0}\end{array}$ \\
\hline
\end{tabular}


Table 6 Prevalence of cough, frequent 'colds', phlegm with 'cold', and effort dyspnoea for non-smokers and regular smokers by gender in the two studies

\begin{tabular}{|c|c|c|c|c|c|c|}
\hline \multirow{2}{*}{ Cross-sectional study } & \multicolumn{2}{|c|}{ Non-smokers } & \multicolumn{2}{|c|}{ Regular smokers } & \multicolumn{2}{|c|}{$\begin{array}{l}\text { Mean weighted difference } \\
\text { Non-smokers } v \text { regular smokers }\end{array}$} \\
\hline & Boys $\%$ & Girls\% & Boys $\%$ & Girls\% & Boys $\%$ & Girls $\%$ \\
\hline \multicolumn{7}{|l|}{$\begin{array}{l}\text { First (1975) } \\
\text { Cough }\end{array}$} \\
\hline Hardly ever & $77 \cdot 1$ & $78 \cdot 4$ & $58 \cdot 5$ & $60 \cdot 2$ & $21^{*}$ & $22 *$ \\
\hline A little on most days & $18 \cdot 2$ & $17 \cdot 1$ & $26 \cdot 8$ & $25 \cdot 0$ & $10^{*}$ & $10^{*}$ \\
\hline A little every day & $4 \cdot \overline{7}$ & $4 \cdot 5$ & $14 \cdot 7$ & $14 \cdot 8$ & $11^{*}$ & $12^{*}$ \\
\hline Often suffer from cold & $32 \cdot 5$ & $34 \cdot 7$ & 40.0 & 46.5 & $9^{*}$ & $13 *$ \\
\hline Phlem with cold & $26 \cdot 3$ & $20 \cdot 3$ & $55 \cdot 5$ & $42 \cdot 9$ & $28^{*}$ & $23 *$ \\
\hline Short of breath on exertion & $14 \cdot 3$ & $22 \cdot 0$ & $25 \cdot 5$ & $44 \cdot 8$ & $14^{*}$ & $25^{*}$ \\
\hline \multicolumn{7}{|l|}{ Second (1979) } \\
\hline Cough & & & & & & \\
\hline Hardly ever & $77 \cdot 7$ & $78 \cdot 5$ & $52 \cdot 1$ & $53 \cdot 9$ & $30 * \dagger$ & $28^{*}$ \\
\hline A little on most days & $17 \cdot 0$ & $16 \cdot 6$ & $32 \cdot 0$ & $30 \cdot 6$ & $17 * \dagger$ & $16 * t$ \\
\hline A little every day & $5 \cdot 3$ & 4.9 & $15 \cdot 9$ & $15 \cdot 5$ & $13^{*}$ & $12^{*}$ \\
\hline Often suffer from cold & $36 \cdot 3$ & $39 \cdot 5$ & $42 \cdot 3$ & $51 \cdot 3$ & $8^{*}$ & $13 *$ \\
\hline Phlegm with cold & 27.0 & $23 \cdot 3$ & $60 \cdot 8$ & $50 \cdot 4$ & $34^{*}$ & $28^{*}$ \\
\hline Short of breath on exertion & $12 \cdot 4$ & $20 \cdot 2$ & $23 \cdot 0$ & $39 \cdot 3$ & $14^{*}$ & $20^{*}$ \\
\hline
\end{tabular}

*Difference significant $\mathbf{P}<0.001$ (Cochran's test).

$\dagger$ Result significantly different from first cross-sectional study $\mathbf{P}<0.05$ ( $t$ statistic).

Table 7 Reported knowledge that smoking causes the following diseases, by gender, in the two studies

\begin{tabular}{|c|c|c|c|c|c|c|}
\hline \multirow{2}{*}{ Cross-sectional study } & \multicolumn{2}{|c|}{ Non-smokers $\dagger$} & \multicolumn{2}{|c|}{ Regular smokers } & \multicolumn{2}{|c|}{$\begin{array}{l}\text { Mean weighted difference } \\
\text { Non-smoker } v \text { regular smokers }\end{array}$} \\
\hline & Boys $\%$ & Girls $\%$ & Boys $\%$ & Girls $\%$ & Boys \% & Girls $\%$ \\
\hline \multicolumn{7}{|l|}{$\overline{\text { First (1975) }}$} \\
\hline Appendicitis & $4 \cdot 6$ & $3 \cdot 3$ & 3.7 & 1.7 & 0 & 1 \\
\hline Chestiness & 80.9 & $82 \cdot 1$ & $83 \cdot 3$ & 90.1 & 1 & 3 \\
\hline Heart disease & $52 \cdot 1$ & $48 \cdot 2$ & $44 \cdot 1$ & 45.5 & $10^{*}$ & 4 \\
\hline Stroke & 15.6 & 14.0 & $14 \cdot 7$ & $14 \cdot 3$ & 1 & 2 \\
\hline Lung cancer & 92.1 & 91.9 & $89 \cdot 3$ & 90.9 & $3^{*}$ & $4^{*}$ \\
\hline Deafness & 3.4 & $3 \cdot 5$ & $2 \cdot 6$ & $2 \cdot 5$ & $\mathbf{0}$ & $i$ \\
\hline Bronchitis & $64 \cdot 2$ & $63 \cdot 5$ & $68 \cdot 3$ & $80 \cdot 8$ & 2 & $8^{*}$ \\
\hline \multicolumn{7}{|l|}{$\begin{array}{l}\text { Bronchitis } \\
\text { Second (1979) }\end{array}$} \\
\hline Appendicitis & 5.4 & 1.3 & $3 \cdot 9$ & 1.2 & 1 & 1 \\
\hline Chestiness & $77 \cdot 4$ & $80 \cdot 3$ & 79.9 & $88 \cdot 7$ & 2 & $5^{*}$ \\
\hline Heart disease & $63.0 \dagger$ & $61 \cdot 8 \dagger$ & $54.8 \dagger$ & $53.4 \dagger$ & $9^{*}$ & $8^{*}$ \\
\hline Stroke & $24.9 \dagger$ & $23 \cdot 1 \dagger$ & $22.6 \dagger$ & $20.0 \dagger$ & 3 & 1 \\
\hline Lung cancer & 94.0 & 95.3 & 89.8 & $93 \cdot 3$ & $5^{*}$ & $3^{*}$ \\
\hline Deafness & $4 \cdot 1$ & $3 \cdot 2$ & $\mathbf{3} \cdot \mathbf{3}$ & 3.0 & 0 & 1 \\
\hline Bronchitis & $64 \cdot 3$ & $67 \cdot 8$ & $72 \cdot 3$ & $78 \cdot 9$ & $\mathbf{0}$ & 3 \\
\hline
\end{tabular}

*Difference significant $\mathbf{P}<0.01$ (Cochran's test).

$\dagger$ Result significantly different from first cross-sectional study, $\mathbf{P}<0.001$.

smoker differences. The non-smokers appear to be more aware of the association with heart disease and lung cancer but the girls who smoke are more aware of the relationship between smoking and chestiness/ bronchitis. Further analysis of the results by age indicates that there is, in both studies, a high degree of knowledge about lung cancer over the age range, while knowledge of other major conditions related to smoking tends to increase with age.

Despite the similarities in the overall pattern of results there are significant differences in the degree of knowledge for two of the conditions listed. The percentage of children linking smoking with heart disease has increased from 48 to $58 \%$ between 1975 and 1979 while the association between smoking and stroke has also risen from 16 to $22 \%$. In both cases the percentage rise is fairly constant across all the smoking categories.

\section{Discussion}

We have obtained results relating to the smoking habits, prevalence of respiratory symptoms, and knowledge of health hazards linked to cigarette smoking in two cross-sectional studies, with an intervening period of 4 years, through the secondary schools of a defined geographical area.

For the purposes of analysis and discussion the two studies are considered in all respects comparable and independent of one another. In strict terms these 
assumptions are incorrect. The studies are not comparable as the 13 schools taking part in each were not the same, one school being unique to each survey. However, separate analyses of the results have been performed to compare these schools with their remaining study populations on the major independent variables and these would indicate no significant differences between them.

The two studies are not independent of one another as those children in the school 1st and 2nd forms in 1975, at the time of the first study, would be in their 5th and 6th forms during the second, 1979 survey. As the questionnaires were answered anonymously an unknown number of children will be represented in both surveys.

We do not believe that these factors significantly affect or invalidate our analyses or conclusions. Within our study area we found that $15 \%$ of the secondary school population were smoking regularly (at least one cigarette a week) in 1975 and that $13 \%$ were smoking regularly in 1979, a fall of $1.5 \%$. The prevalence varied widely with age, increasing steadily from $3-4 \%$ at age 11 years up to $20-25 \%$ at 16 years, the minimum school leaving age, and thereafter tending to fall. This fall is almost certainly related to the inverse association between smoking and academic achievement. ${ }^{1}$

The results, comparing the smoking rates between the genders, would confirm and support conclusions reached from previous large-scale studies, in that there is a continuing fall in the smoking rates for boys- $16.3 \%$ in $1975,13.1 \%$ in 1979 -while for girls there has been little change or even an increase $-13.3 \%$ in $1975,13.7 \%$ in 1979 . It is interesting to note that for the first time, at all ages between 12 and 15 years the smoking rates of girls in 1979 exceed those of the boys.

While these results are in general agreement with the trend in smoking habits deduced from the analysis of a series of studies performed during the last 20 years employing widely different study designs they do not agree with the data from a comparable study performed by Banks et al. ${ }^{8}$ in Derbyshire. In that study 11 to 12 and 14 to 15 -year-old children, in randomly selected secondary schools, were screened in 1974 and then again in 1977. The results suggested that during this period boys' smoking habits remained constant but that of the girls showed a significant decline. ${ }^{9}$ Other significant differences between the present study and the Derbyshire study can be noted; in particular our results indicate an increase in the prevalence of children experimenting with smoking rather than a decrease as in the Derbyshire study. Although the differences between these studies cannot readily be explained, the overall findings do not indicate that the incidence of smoking in young people is diminishing. This can be underlined by considering changes in cigarette consumption levels, for although the prevalence of smoking in boys may be declining and that in girls stabilising, the number of cigarettes being smoked by the regular smokers is in general increasing. In 1979 we find that $73 \%$ of boys and $68 \%$ of girls who are regular smokers are smoking on average at least 1 clgarette a day and this compares with $66 \%$ of boys and $65 \%$ of girls in 1975.

The analysis of the tar category of cigarettes smoked by those regular smokers who normally smoke one brand of cigarette would suggest that although the majority of young people are smoking middle tar products an increasing number are smoking low tar cigarettes. However the increase from less than $1 \%$ in 1975 to $6 \%$ in 1979 , which is at the expense of low-middle tar smoking rather than middle tar smoking, is probably owing to the relative increase in the low tar sector of the market secondary to the reduction of tar levels in popular brands marketed as low-middle tar in 1975 together with the increasing number of new low tar brands introduced into the market. It is interesting to note that the levels of low tar smoking by young people are well below the estimated levels of about $4 \%$ and $15 \%$ respectively for the adult populations in 1975 and 1979 , and this would support the observation that young people generally prefer moderately 'highyield' cigarettes. ${ }^{10}$ It has been suggested ${ }^{11}$ that low tar cigarettes might facilitate taking up the smoking habit by young people as such cigarettes would reduce the aversive physical response to early smoking episodes that might otherwise deter from taking up the habit. The results from the small proportion of experimental smokers who smoke a single brand of cigarette, in the present study, might support this suggestion, in that far more of them (about $20 \%$ in 1979) are smoking low tar cigarettes.

The analysis of respiratory symptoms and smoking habits shows a remarkable consistency between the two studies, thus stressing the strength of the relationships. Young people who are regularly smoking, even at age 11 years, show a significantly higher incidence of cough and phlegm production, admit to more exertional dyspnoea, and state that they suffer more often from respiratory tract infections than the non-smokers. At the same time the study results show an increasing knowledge of the smokingassociated health conditions and in particular of the relationship with heart disease. It is interesting that although knowledge of the associations between smoking and lung cancer remains high and while knowledge of the association with heart disease (stroke) increases, the reported knowledge of the association with 'chestiness' and bronchitis remains 
steady at about $75 \%$. This last association is present in the young people when they are young, and therefore knowledge of it would be most relevant to their attitude to smoking.

It becomes increasingly apparent that specific health education relating to future mortality/ morbidity statistics of the smoking associated diseases does not deter children from taking up the smoking habit or encourage those who are already regular smokers to give up. There would appear to be considerable need for research into the most appropriate form of health education.

We thank Dr R L Linden, Area Medical Officer, Mr P J Lee, Director of Education, Dr G Webster, Specialist in Community Medicine (Child Health), and their staff; secondary school head teachers and their staff; all parents and children within the borough of Hounslow whose co-operation made this study possible; Dr K MacRae, senior lecturer in medical statistics, Charing Cross Hospital Medical School, for statistical advice.

\section{References}

1 Bewley B R, Day I, Ide L. Smoking by children in Great Britain-a review of the literature. London: Social Science Research Council/Medical Research Council, 1973: 3-6.

2 Rawbone R G, Keeling C A, Jenkins A, Guz A. Cigarette smoking among secondary schoolchildren in 1975. $J$ Epidemiol Community Health 1978; 32: 53-8.
${ }^{3}$ Rawbone R G, Keeling C A, Jenkins A, Guz A. Cigarette smoking among secondary schoolchildren in 1975: its prevalence and some of the factors that promote smoking. Health Educ J 1978; 38: 92-9.

4 Nie N H, Hull C H, Jenkins J G, Steinbrenner K, Bent DH. Statistical package for social sciences, second edition. New York: McGraw-Hill, 1975: 218-48.

5 Maxwell A E. Analysing qualitative data. London: Chapman \& Hall, 1961: 52-62.

- Cochran W G. Some methods for strengthening the common $\chi^{2}$ tests. Biometrics 1954 ; 10 : 417-51.

7 Government Chemist. Report: Tar and nicotine yields of cigarettes. August 1974-January 1975; February-July 1978. London: HMSO, 1976; 1979: 96, Table 15; 60, Table 5.2.

8 Banks M, Bewley B R, Bland J M, Dean J R, Pollard V. A longterm study of smoking by secondary schoolchildren. Arch Dis Child 1977; 53: 12-9.

9 Bewley B R. Juvenile smoking-patterns and trends. In: Ramstrom L M, ed. The smoking epidemic, a matter of worldwide concern. Proceedings of the Fourth World Conference on Smoking and Health, Stockholm 1979. Stockholm: Almquist \& Wiksell, 1980: 69-71.

10 The Surgeon General. Report: The health consequences of smoking for women. Part 3. Psychosocial and behavioral aspects of smoking in women. Washington: US Department of Health, Education, and Welfare, 1980: 271.

11 The Surgeon General. Report: The health consequences of smoking - the changing cigarette. Section 7. Behavioral aspects. Washington: US Department of Health and Human Services, 1980: 173.

Correspondence to Dr R G Rawbone, Department of Physiology, Medical Biology Centre, Queen's University of Belfast, 97 Lisburn Road, Belfast BT9 7BL.

Received 17 November 1981 